\title{
Design of automatic eggs hatchery as preservation of turtle in coastal of East Java
}

\author{
Sukandar ${ }^{1,2}$, Sunardi ${ }^{1,2}$, Mihrobi Khalwatu ${ }^{1,2}$, Muhammad Arif Rahman ${ }^{1,2}$, and Zainal \\ Abidin $^{1}$ \\ ${ }^{1}$ Fisheries Department, FFMS Universitas Brawijaya, Malang, Indonesia \\ ${ }^{2}$ IMFISHER Research Group, Universitas Brawijaya, Indonesia
}

\begin{abstract}
There are 6 of 7 species of sea turtles in the world found in Indonesia. Meanwhile, the existence of sea turtles is currently experiencing a very drastic decline. This research is one of the conservation efforts to increase the number of sea turtles in several turtle conservation areas in East Java. From the experimental results, the temperature is the most influential factor in the sex determination. The development of egg incubation technology in this study has resulted in hatching results with the number of male sex dominant than female. To produce male eggs the temperature in the hatching media is between $25^{\circ} \mathrm{C}-30^{\circ} \mathrm{C}$, while the optimal temperature for hatching female eggs is $>30^{\circ} \mathrm{C}$. The artificial turtle egg incubator technology is designed in such a way that the conditions in the hatching chamber are close to the hatching conditions in nature with a temperature that can be set with an incandescent lamp equipped with a temperature sensor, when the high temperature the temperature sensor will work and the incandescent lamp automatically turns off. Optimum moisture conditions of about $70 \%$ water content can be regulated by the humidity sensor, when humidity is reduced, it can automatically spray water.
\end{abstract}

\section{Introduction}

Turtles are protected fauna because their populations are endangered according to International Union for the Conservation Nature (IUCN) regulations [1]. In the world there are 7 species of sea turtles and 6 of them are found in Indonesia spread in 34 provinces along the coast, but natural factors such as high temperature and sand humidity due to climate change pose a significant threat to the development of hatchlings (turtle hatchlings), if nest temperatures exceed the range normal then the percentage of hatching tends to be slightly $40 \%$ successful and $60 \%$ failed. Unstable temperature and humidity also affect embryos of female hatchlings with more percentages than male hatchlings, even though in nature the process of breeding female turtles requires six males to be fertilized (1:6) male hatchlings appeal. Recent studies on the sex comparison of sea turtles provide surprising results. The study revealed that $99 \%$ of light green turtles from the northern Great Barrier Reef in Australia were female, while male turtles began to disappear [4]. It is very dangerous for the sustainability of sea turtle species in the world. This research is one of the 
efforts to increase the success of hatching existing turtle eggs and increase the ratio of the number of hatching eggs of male turtles from hatching.

\section{Methods}

The method used in this study is the method of observation with field observations to determine the critical determinants variables of success in hatching turtle eggs. Another method used is parametric design, a method for making the design and production of incubator system by considering all the variables needed by an automatic turtle egg incubator to produce the most optimal turtle egg incubator design.

\section{Results}

Some factors that determine the success of hatching turtle eggs are temperature, number of eggs and egg age [2]. Semi-natural hatching eggs experience many failures caused by predatory animals, microbial infections and damage to the spawning environment [6]

The difference in incubation time is caused by different temperature fluctuations, the higher the temperature the faster the incubation period and the lower the incubation period will be relatively longer. The incubation period also influences the success of the hatchery [5], the longer the egg incubation period, the smaller the percentage of hatching success.

The average temperature on the sensor tool is $31.4^{\circ} \mathrm{C}$, while the average temperature in the sand is $30.79{ }^{\circ} \mathrm{C}$ [7], if the temperature during the incubation period is much lower or higher than the optimal temperature of $28^{\circ} \mathrm{C}-32^{\circ} \mathrm{C}$, then the hatching results will be less than $50 \%$. The temperature in the automatic eggs turtles incubator is relatively stable. During the hatching process the surface temperature and temperature fluctuations in the sand range between the optimum fluctuation value of the tool that is $25^{\circ} \mathrm{C}-32^{\circ} \mathrm{C}$.

Temperature conditioning using yellow incandescent lamps with 15 watts of power of 2 lamps. To maintain temperature stability automatically controlled with an electric sensor, so that when the temperature is above $30^{\circ} \mathrm{C}$, the lamp will automatically turn off. Optimum temperature of $25^{\circ} \mathrm{C}-30^{\circ} \mathrm{C}$.

Moisture conditioning, if the humidity sensor detects the water content in the hatch media is not in accordance with the set point, then the water supply will turn on and moisten the hatching media. optimal humidity of $70-80 \%$ moisture content. 


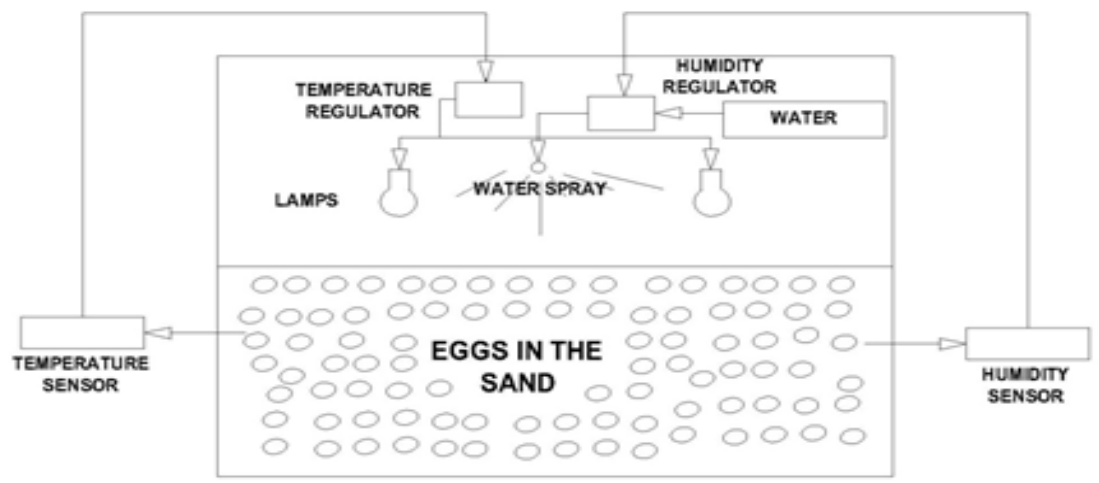

Fig. 1. Hatching scheme for automatic turtle eggs incubator

The results of the experiment showed that from 75 eggs during the 46-day incubation period, 27 eggs were incubated from 30 eggs that were hatched or about $90 \%$ of the eggs could hatch.

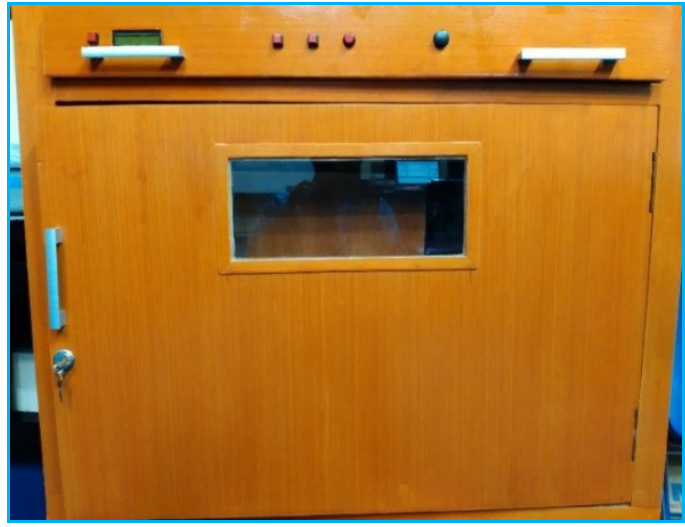

Fig. 2. The results of the automatic turtle eggs incubator production

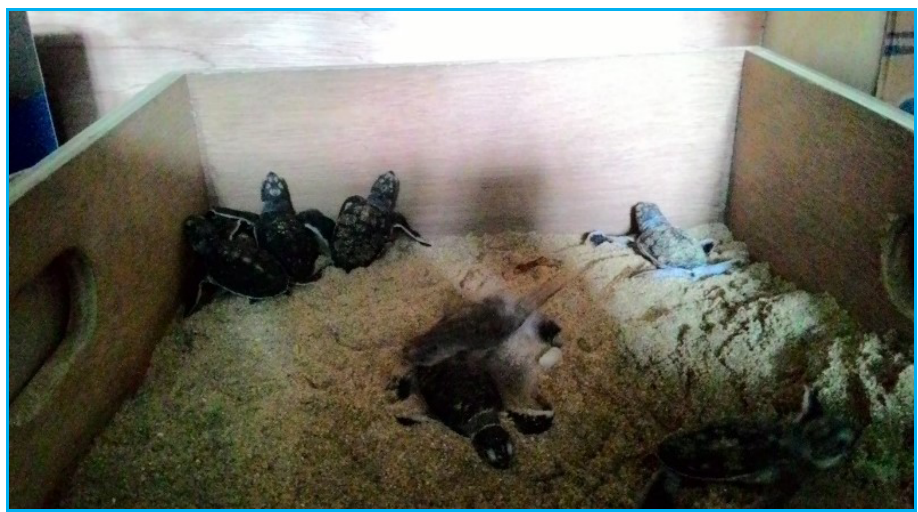

Fig. 3. The results of hatching turtle eggs in the automatic turtle eggs incubator

The development of turtle egg incubator technology has so far come to the development of automatic technology that is equipped with temperature, humidity sensors. In addition, to monitor the results of hatching has been connected to the LCD screen and the control system can be controlled by using Bluetooth. Sand media are still maintained as the best 
media for hatching eggs and equipped with an android-based micro controller in running the program. The advantages of this system can accelerate the percentage of hatching eggs up to $90 \%$ and the tendency of sex control of hatchlings (turtles) male / female dominance by temperature and humidity factors that are equipped with a temperature sensor detection system in the sand, a moisture detection sensor inside sand that has been determined / regulated, the electrical component system is equipped with a Bluetooth connectivity system, USB serial connect to PC, LCD display screen (temperature and humidity display), CCTV Camera (display of the process of turtle eggs hatching / hatchling out of the sand) in the box that is in the program automatically and a mechanical box incubator system with a capacity of 150 turtle eggs.

\section{Conclusions}

Artificial turtle egg incubator technology has been proven to increase the success rate of turtle egg hatching in East Java. Conditioning the room with an optimal temperature between $24^{\circ} \mathrm{C}-25^{\circ} \mathrm{C}-30{ }^{\circ} \mathrm{C}$, and a humidity of around $70 \%$ is very suitable for the process of hatching turtle eggs. the addition of automatic sensors for temperature and humidity control makes it easy to use an artificial turtle egg incubator which has been successfully tested with a success rate of up to $90 \%$ of the total hatched turtle eggs.

KEMENRISTEKDIKTI which has funded research through the 2019 Campus Innovation Business Product Development (PPUPIK) scheme. Brawijaya University has helped provide workshop facilities and product displays.

\section{References}

1. R. Ario, E. Wibowo, I. Pratikto,S. Fajar, Jurnal Kelautan Tropis 19(1), 60-6 (2016)

2. E. Mardiana, A. Pratomo, H. Irawan, Hatchling rate of C. midas in Wie Tambelan Islan of Lagoi (Repository UMRAH, 2013)

3. F. Listiani, H. Mahardhika, N. Prayoga, Omni-Akuatika 14(20), 63-8 (2015)

4. D. Dobbs, C. Limpus, A. Landry, K. Dobbs, J. Miller, A. Landry-Wheeler, B. Landry, Chelonian Conservation and Biology (1999)

5. X. Fransiskus, L. Amin, The impact of the depth of semi natural nest to incubation period of L. olivacea (Undergraduate Thesis, Malang, 2012)

6. Rudiana E, Ismunarti DH, Nirwani N., Indonesian Journal of Marine Sciences 9(4), 200-5 (2004)

7. Patrício AR, Marques A, Barbosa C, Broderick AC, Godley BJ, Hawkes LA, Rebelo R, Regalla A, Catry P. Marine Ecology Progress Series 18, 577, 189-203 (2017) 